\title{
The Human Resource function contribution to human development in South Africa
}

\author{
Authors: \\ Penny Abbott ${ }^{1}$ \\ Xenia Goosen ${ }^{1}$ \\ Jos Coetzee ${ }^{1}$ \\ Affiliations: \\ ${ }^{1}$ Department of Industrial \\ Psychology and People \\ Management, University of \\ Johannesburg, South Africa \\ Correspondence to: \\ Penny Abbott \\ Email: \\ pennyabbott@mweb.co.za \\ Postal address: \\ 4a Birnam Road, Forest \\ Town, Johannesburg 2193 , \\ South Africa \\ Dates: \\ Received: 07 Sept. 2011 \\ Accepted: 18 May 2013 \\ Published: 18 Sept. 2013 \\ How to cite this article: \\ Abbott, P., Goosen, X., \\ \& Coetzee, J. (2013). \\ The Human Resource \\ function contribution to \\ human development in \\ South Africa. SA Journal \\ of Human resource \\ management/SA Tydskrif vir \\ Menslikehulpbronbestuur, \\ 11(1), Art. \#408. 14 pages. \\ http://dx.doi.org/10.4102/ \\ sajhrm.v11i1.408

\section{Copyright:} \\ (C) 2013. The Authors. \\ Licensee: AOSIS \\ OpenJournals. This work \\ is licensed under the \\ Creative Commons \\ Attribution License.
}

Read online:

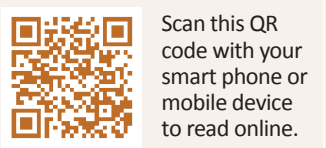

Orientation: This article discusses the extent to which human under-development in South Africa and the consequent societal problems of poverty and inequality are addressed by the work of HR practitioners.

Research purpose: The purpose of the study was to provide empirical evidence of the appropriateness of current HR practice in South African socio-economic conditions and to make suggestions for improvement.

Motivation for the study: Societal problems caused by human under-development are impacting more and more on organisations in South Africa. It is currently not known to what extent and in what way HR work contributes to the improvement of this situation.

Research design and method: An interpretive approach was adopted. Qualitative methods within a basic qualitative study strategy were used, including interviewing and a focus group. A sample of 50 individual HR practitioners at various organisational levels was interviewed. Data were analysed by means of thematic analysis.

Main findings: Societal problems caused by human under-development impact tremendously on the daily work of HR practitioners. Many HR practitioners do play an Employee Advocate role within the workplace but do not see this role as extending further to any degree. Some role models of more strategic responses were found.

Practical/managerial implications: HR practitioners would better fulfil their mandate to work for the success of their organisation if they took pro-active steps to accelerate human development outside their organisations.

Contribution/value-add: Empirical evidence is presented to support efforts to broaden the focus of HR work to human development. This linkage has not previously been researched.

\section{Introduction}

Almost by definition, the role of HR practitioners is concerned with people development. It may, however, be asked whether they can achieve success in this area if their organisations are situated in a society with generally low levels of human development. More than 15 years ago, Ulrich and researchers at the University of Michigan (Ulrich, 1997) said that one of the key roles of an HR practitioner was that of Employee Champion; it was later changed to that of Employee Advocate. This article will explore whether the time has come in South Africa to reaffirm the importance of that role and redefine it to that of People Advocate, so that it refers to people both inside and outside the organisation:

If successful, the HR professional has the opportunity to become central to the effectiveness not only of their organisation but to also have an impact on the social and economic environment in which they operate. If there was ever a time in the sun for HR that time is now (Boninelli \& Meyer, 2011, p. 446).

Seventeen years after the first democratic elections in South Africa the indicators of quality of life for the large majority of the population of the country show that insufficient progress has been made in reducing inequality, poverty and quality of life (UNDP, 2010a). Although the economic status of the country is, in international comparative terms, described as 'upper middle income', large numbers of extremely poor people have little opportunity to participate in and benefit from the economy (NPC, 2011). South Africa is a divided and unequal society (NPC, 2011), but, as Ramphele (2009) pointed out, we have only one economy and it is the distribution of the benefits that divides society.

Human Resource (HR) practitioners work almost exclusively in the formal sectors of the economy (including the public sector), and in organisations of 150 employees or more. They therefore interact with, or impact on, considerably fewer than the 9.2 million people employed in the formal sector ( $18 \%$ of the population). Much modern HR work has to do with sophisticated HR 
practices aimed at engaging knowledge workers in order to drive organisational success in a modern, global business world (Boninelli \& Meyer, 2011). Can it therefore be said that HR work is elitist and that HR practitioners work in splendid isolation, oblivious of the inequalities of society and the ravaging effects of the poverty around them?

Little attention has been paid to the linkage between HR work and human development in the country. Some influential HR commentators in South Africa introduced the idea in 2009 that HR practice rooted in the developed world was not appropriate in the specific context of developing countries in general and South Africa in particular (Crous, 2010; Sibiya, 2010). The purpose of this research study, carried out during 2010 and 2011, was to investigate whether this was true and, if it was true, to find ways in which South African HR practice could be developed so as to be more appropriate in the South African context.

There are few references in the literature to the linkage between HRM (human resource management) and human development. Researchers in the contextual paradigm of HRM (e.g. Brewster, 2007) have emphasised the interaction between societal institutions, national and local culture and HRM, but have not specifically discussed the interaction of the level of human development in a society and HRM practice. In a series of research studies conducted after 1997 Ulrich, Brockbank, Johnson, Sandholtz and Younger (2008) made the first mention of the necessity for HR practitioners to interpret social context in relation to the organisation's HR strategy. In South Africa, commentators such as Nel (2010) and Bernstein (2010) discussed the role of business in societal development, but make no specific mention of HRM in this role.

The research problem for the research study was that HRM as practised in South Africa was not aligned to its socio-economic context. The research objectives included exploration of HR practitioners' perceptions of the appropriateness of what they did in their work relative to the socio-economic context; the construction of a framework for more appropriate practice; and an exploration of factors which would influence the implementation of such a framework.

At present there is little academic work based on empirical evidence which explores the linkage between HR work and human development. Insights and knowledge gained from this study can help to inform education and training institutions, individual HR practitioners and HR professional bodies about the linkage and about ways to work with that linkage to improve human development and therefore, ultimately, the success of organisations and society.

The next section presents a review of the literature in fields relevant to the research. The research design chosen to meet the research objectives is then presented, followed by the research findings relevant to this article. The article ends with a discussion, conclusions and recommendations.

\section{Critical evaluation of the literature}

The literature is explored firstly by working from concepts of human development to concepts of the development of HRM, and secondly by looking at literature linking the two fields, which is the specific focus of this research.

\section{Human development}

The concept of human development is explored in the discipline of development economics which evolved during the 20th century. Some economists realised that countries which had not been industrialised by the mid1950s would not be able to follow the same path of economic development as the older industrialised countries because the world had changed since those countries had become industrialised (Todaro \& Smith, 2006). The philosophy of economic development was debated and a school of thought evolved according to which human development was the primary purpose of economic development. In other words, economic development should not aim simply at improving the material aspects of human life, but also the quality of that life in broad terms. Amartya Sen, the 1998 Nobel laureate in Economics, was a pioneer of this school of thought. He developed the 'capability approach', which is concerned with the ability or non-ability of a poor person to function and live as a decent human being (Evans, 2002; Todaro \& Smith, 2006).

The National Development Plan adopted by the South African Government in 2012 is based on this capability approach, which emphasises the freedom of individuals to exercise social choices and choose what they value. The capability approach is the basis of modern methods of measuring human development, such as the human development index (HDI) (UNDP, 2010b). The HDI measures progress towards three end products of development: longevity (life expectancy at birth); knowledge (adult literacy and years of schooling); and standard of living as measured by real per capita income. A more recent and even broader measurement of human development is the Gross National Happiness Index, which measures psychological well-being, time use, community vitality, culture, health, education, environmental diversity, living standard and governance (GNHI, 2011). A report for the UNDP in 2010 stated that:

... the correlation between economic growth and changes in
the non-income components of human development over
their period of study [1970-2009] is nearly zero. These results
suggest that the oft-repeated dictum that growth is a necessary
condition for increasing human development is simply not true
(Rodriguez, 2010).

This would imply that improved human development is more dependent on policy choices and intervention implementation than on economic growth.

\section{Development of HRM}

Simultaneously to the developments in this school of economic theory there were profound changes in the world of work, brought about by the advent of the knowledge 
and information economy. The globalisation of the world's economy and businesses also led to massive changes in the way companies were managed (Pugh \& Hickson, 2000). In parallel to these changes in the world of work and management approaches, the evolution of human resource management (HRM) followed a path described by Toulson and Defryn (2007) as leading from welfarist (looking after employee interests) to technicist (looking after employee efficiency) and by other researchers as leading from operational to strategic (Ulrich, 1997). Authors such as Jackson (2004) had misgivings about the trend of this evolution, believing that the underlying values of organisations were moving from a humanistic value system to an instrumental value system, to the detriment of the people employed by organisations. However, most HRM research has promoted the move of HRM in the direction of becoming more strategic.

Ulrich (1997) and his co-researchers have expressed this trend in various models of the roles of HR practitioners and the competencies required to enact those roles successfully. Ulrich originally proposed four roles for HRM, all of which had to be held in balance with one another in order to produce successful organisational outcomes. These four roles were revised in Ulrich and Brockbank (2005) in a model which emphasised the integration of all four roles in the HR leader's role. The competencies required to fulfil these roles have been variously described by these researchers, with the latest model being published in Ulrich et al. (2008). The models are summarised in Figure 1.

The message that these models was intended to convey, that HR work is complex but all aspects need to be held in balance, has been somewhat submerged by the concept of HR as a business partner. This concept emerged through work led by Ulrich, which began to focus on the deliverables of HRM rather than the work itself (Ulrich \& Brockbank, 2010). These authors originally intended that HR practitioners would be equal partners, bringing knowledge of organisational behaviour to the implementation of business strategy, being 'partners to the business as they work to create value for employees, customers, shareholders, communities, and management' (Ulrich \& Brockbank, 2010, p. 2). However, in many cases HR practitioners have interpreted this to mean that they must only address problems raised by line managers, rather than bring their own observations and expertise to the discussion, thereby subordinating the HR agenda to the line managers' agenda. This subordination has left some HR practitioners feeling that their professionalism has been diminished.

A further concept important for the purposes of this article is that of the competing paradigms of universalist versus contextual HRM. These paradigms have been elucidated in the work of researchers such as Brewster (2007). The paradigms emerged in response to the globalisation of the world's economy which saw the entry of increasing numbers of companies into foreign markets. The question asked in this type of research has been: Is it appropriate to assume that

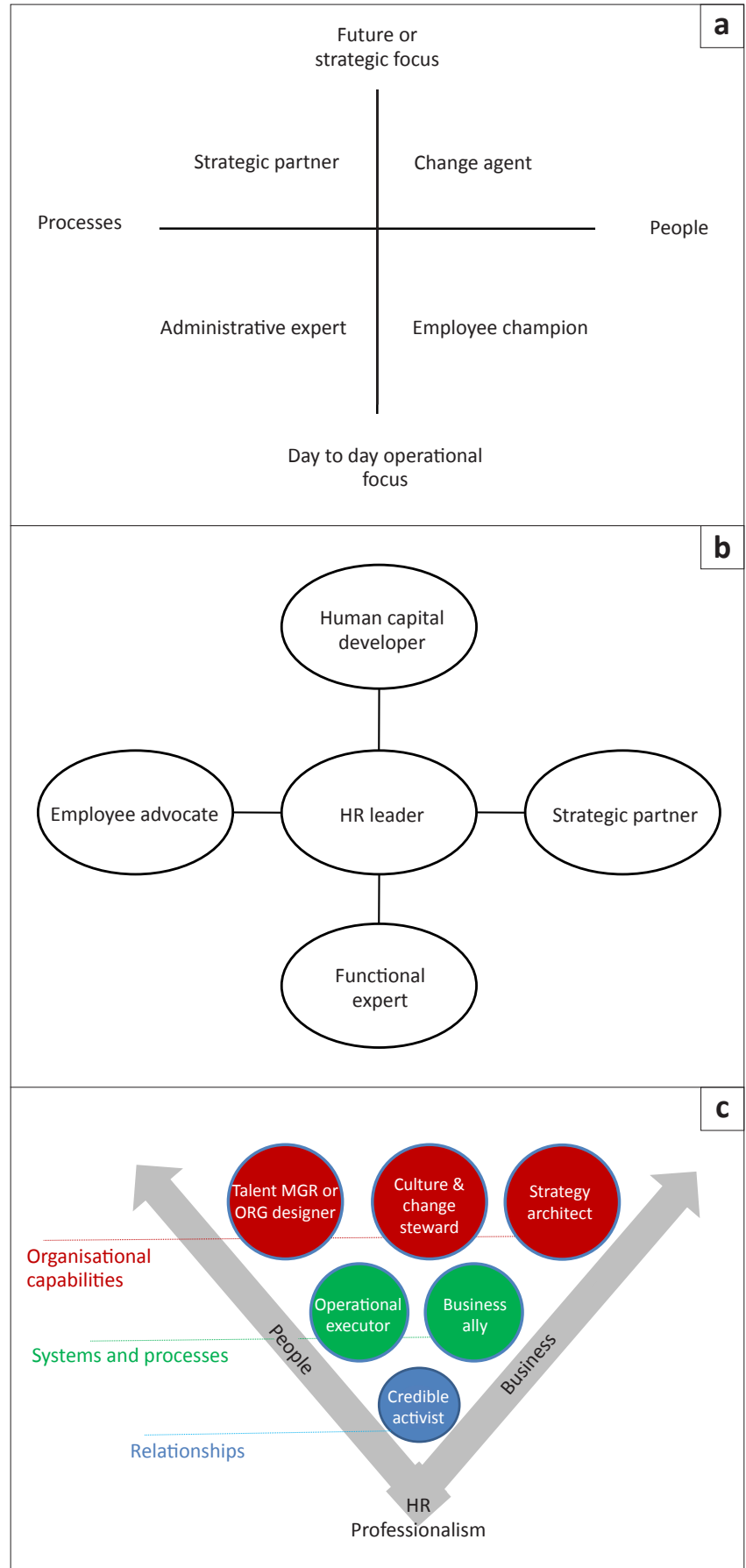

Sources: (a) Ulrich, D. (1997). Human resource champions: The next agenda for adding value and delivering results. Boston, MA: Harvard Business School Press; (b) Ulrich, D., $\&$ Brockbank, W. (2005). The HR value proposition. Boston, MA: Harvard Business School Press; (c) Ulrich, D., Brockbank, W., Johnson, D., Sandholtz, K., \& Younger, J. (2008). Human Resource competencies: Mastery at the intersection
Alexandria, MA: Society for Human Resource Management.

FIGURE 1: Evolution of multiple role models of HRM (a) phase 1 of the HRM role model, (b) phase 2 of the HRM role model, (c) phase 3 of the HRM role model.

HR practices from the home country can be exported without adaptation to the new market? Persuasive conclusions from this research are that conditions in different countries differ to such an extent that HR practices have to be tailored to suit local conditions. These conditions may include variations in culture, institutions and labour market functioning (Brewster, 2007). There is evidence that, when compared over time, HR practices in different countries are sometimes on a diverging 
path, sometimes on a converging path and sometimes 'crossverge' (that is, they influence one another and end up with a new adaptation of practice) (McGaughey \& De Cieri, 1999). Ulrich et al. (2008) discovered significant differences in HR practice in China compared to the rest of the world and remarked that these differences probably reflected the early stages of development of the HR function in that country. His discovery introduced maturity of the HR function itself as another variable in HR practice. Ulrich, Brockbank, Younger and Ulrich (2012) have since explored differences across the world to determine how the HR function adds value to organisations.

\section{South African economic development and HRM}

South Africa faces severe social and economic problems. The levels of unemployment and inequality in the country are much higher than they should be, given the country's level of resources, and contribute negatively to almost every index of comparison with other countries (Bernstein, 2010; NPC, 2011; Turok, 2008).

South Africa is, like any less-developed country, unique (Todaro \& Smith, 2006). Economic development in this country has been influenced not only by global economic trends, but also by the distortions in the economy that occurred under colonial and apartheid governments during the 20th century (Turok, 2008). This resulted in an economy unprepared in many ways for its re-entry into the globalised economy after 1990. Today South Africa attempts to compete with other countries on the basis of an under-developed socio-economic infrastructure.

Unfortunately there is little consensus between major institutions in the country as to the appropriate route to improved human development in South Africa. The policies of the Government have emphasised macro-economic stability and growth as the basis from which to fund improvements in human development (Turok, 2008), but the development funded by these macro-economic policies has not occurred on a scale to meet either the needs or the expectations of the majority of the population (NPC, 2011). The indicators of human development in South Africa deteriorated markedly between 1990 and 2006 and have since recovered only slightly; whilst in other developing countries the indicators have improved considerably (see Figure 2).

Business, as an institution, has not been effective in adopting a useful approach to human development, nor a sound basis for engagement with the Government on this matter. The business lobby maintains the 'trickle-down' approach and blames the lack of development on poor delivery by Government. Recently, influential authors and business leaders have been saying that business will have to find new approaches to both of these issues (Bernstein, 2010; Mills, 2010).

In addition, corporate governance worldwide has realised that the sustainability of business depends on better corporate

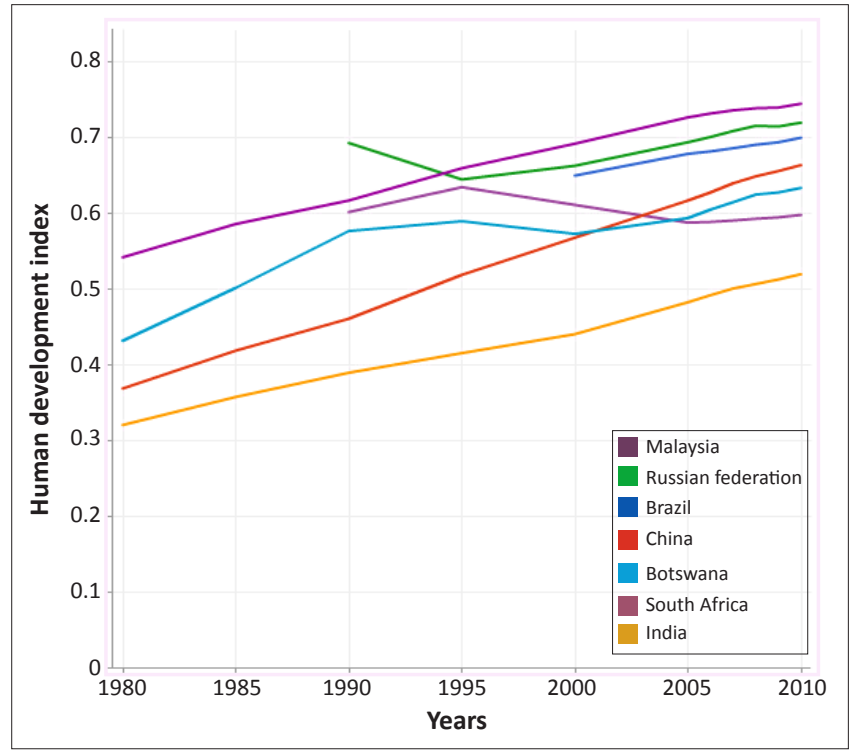

Source: United Nations Development Programme. (2011). Human Development Report. Retrieved July 06, 2011, from http://hdr.undp.org/en/data/explorer/

FIGURE 2: Human development index trends.

citizenship, and this has effectively ended the debate about the role of business in society. The King III Report (IOD, 2009) and the Companies Act (Republic of South Africa, 2008) both emphasised that a company must play a pro-active and large role in relation to its social context. Conditions prevailing in this social context were summarised in the Diagnostic Overview by the National Planning Commission (NPC, 2011). This report indicated that, unless action was taken, the markets as well as human and social capital available to organisations would not in the future be of a quality to ensure organisational success.

The challenges of transformation in South Africa go beyond economic development to issues about how people interact with one another and cooperate to the good of society as a whole (Nel, 2010; NPC, 2011; Ramphele, 2008). Since 1994 an enormous amount of legislation has been passed to change employment practices and to force companies to act constructively to bring about both social and economic transformation. These transformation imperatives set a major part of the agenda for HR practice in South Africa, and if these imperatives are seen in combination with the global issues impacting on the workplace, such as the global talent shortage, global labour mobility, the impact of technology and generational differences, it becomes clear why the HR agenda is overcrowded (Boninelli \& Meyer, 2011).

However, the contribution actually made by HR practitioners to human development in South Africa may be restricted to their work within the organisation and even then their contribution may be insignificant. There is little direct information available on the extent to which HR practitioners make a contribution to human development but there is a considerable body of evidence on deficiencies in areas falling within the scope of HR work. Examples include the fact that skills development has been lagging badly (Temkin, 2010; Turok, 2008) and the fact that industrial relations 
structures appear to be unable to deliver the constructive relationships necessary for industrial peace (Thompson, 2011). Employment Equity advances are also not happening as fast as they should, and here a shocking example is the lack of improvement in the employment of disabled people (EE Commission, 2010). Nel (2010) reported that his surveys since 1985 on transformational leadership practices within South African businesses showed that towards the end of the 2000s more than half the managers he surveyed believed that their organisations were still largely untransformed.

The Broad-Based Black Economic Empowerment (BBBEE) policy approach recognises that companies must play a more constructive role in transforming the economy and society. Corporate social investment (CSI) requirements are built into the BBBEE approach. However, BBBEE and CSI are often not incorporated into the HR function of a business organisation and it has been the author's personal experience that the HR function is often not even involved in any way in the organisation's CSI programmes. Regarding contributions by HR practitioners to improve pipelines of educated and skilled people, no such contributions have been documented at the time of writing this article.

\section{Nel believed that:}

Business is not only an extraordinarily powerful influence in society, but it enjoys almost unparalleled capacity to exercise constructive influence in society. In the early 1990s South African leaders proved they had the imagination and wherewithal to develop historic breakthroughs in driving the thinking and later action that delivered our political transformation. The 'class of 2010 ' has to now step up to the mark and get things moving along a road of long-term sustainable solutions. (2010, p. 190)

\section{Research design \\ Research approach}

This study adopted an interpretive approach, which is suitable for developing an insightful understanding of HR practitioners' perceptions. The meanings that HR practitioners may attach to their work are individual and subjective. The interpretive approach does not search for universal truths but brings to light individual HR practitioners' subjective perceptions of the current and future role of HR.

The research objectives were exploratory in nature, as the study did not start from a position of having a theory to test. Instead, the aim was to develop a framework from ideas and insights formulated during an exploration of the topic. The author as researcher was playing an insider role, having been an HR practitioner for many years, and could therefore use insights based on her experience to interpret the research findings. These factors led the researcher to choose the interpretive approach.

\section{Research strategy}

In order to explore the research problem thoroughly, data were collected from a wide variety of settings and from a large number of people. Using an approach elaborated by Caelli, Ray and Mill (2003), a basic qualitative research strategy was chosen. The advantages of this type of strategy were enumerated by Merriam (1998, p. 11) and one of these is the fact that it allows the researcher to 'discover and understand the perspectives and worldviews of the people involved.' The strategy involves description, interpretation and understanding.

Within this strategy, the form of study chosen was a crosssectional design, the units of analysis being individual HR practitioners in organisations. Bryman and Bell (2003) described the typical form of a cross-sectional design as interviews at a single point in time with the aim of identifying patterns of association.

In qualitative research the chosen strategy may lead to a literature review being conducted prior to or after the collection of data, depending on the theory approach chosen. The researcher chose to conduct a literature survey prior to commencing the collection of data in order to frame the topic on some basic theories of human development and HRM. Additional literature was consulted after data collection in order to provide a theoretical basis for insights derived from the data.

\section{Research method Research setting}

This research study focused only on HR practitioners in positions providing HR services to employees of the organisation, and therefore excluded consultants, recruitment agencies and training providers. The setting of the research was within organisations. Data were initially collected from many kinds of organisations, including private; public and non-government (NGO) sector organisations. At the data analysis stage, however, it was found that the issues reported in the public sector differed markedly from those from other kinds of organisations, and the decision was made to exclude data from the public sector in order to maintain focus on the research objectives.

An additional focus of the study, not discussed in this article, was to examine the HR profession as a whole in South Africa.

\section{Entrée and establishing researcher role}

Phase 1 of the research involved collecting data from a set of informed commentators (people knowledgeable about HR work, but not practising currently, except in one case) about their views on HR practice. Access to these commentators was gained directly by the researcher, sometimes from her own network and in a few cases by referral from other contacts. An explanation of the purpose of the research and an invitation to participate were sent to the participants by e-mail. Permission was obtained from them for their views to be attributed.

Phase 2 of the research involved approaching practitioners directly to collect data about their perceptions and 
experiences. The total population of HR practitioners in South Africa is unknown. There is a known population of practitioners who are registered with the South African Board for People Practice (SABPP) or are members of other professional associations in the field, but according to estimates in the profession, these people represent a minority of HR practitioners in South Africa. Access to participants of the study was therefore obtained through gatekeepers holding data-bases of e-mail addresses obtained from other sources. These included two universities (for access to their post-graduate HRM students) and a large retailer of business books, conferences and training courses in South Africa. An e-mail was sent out through those gatekeepers to invite participation in telephone interviews on the topic, which was briefly explained. Participation in this part of the research was therefore voluntary and self-selected.

A focus group met in the final phase of the research to discuss whether some of the early findings were resonating with them. The research and the focus group were announced at a conference of HR executives held in March 2011 by the gatekeeper (the organiser of the conference) and volunteers were requested.

Sampling: Purposeful sampling was used for the first group of commentators, and a maximum variation sampling strategy was used (Patton 2001). When this strategy is used, a sample is chosen from which common themes can be derived even from participants who vary widely on chosen dimensions. Participants were chosen who could give views based on different fields of interaction with HR work: consultants, academics, a government policy adviser, organised business groups, HR professional body office holders current and past, and ex-HR practitioners now in other business capacities. A total of 17 interviews were held with this group of participants.

For the main group of HR practitioner participants, a target sample size of 50 was set as being able to give reasonable coverage of a diversity of work settings but at the same time be manageable within the resources of the researcher. The sampling approach was convenience sampling because purposeful sampling strategies were not possible with this widespread and completely unknown population. The gatekeepers' address lists could not be filtered to fit only this research study's targeted population and hence the e-mailed invitation was sent to more than 25000 recipients. However, the e-mail did set out clear inclusion criteria, and as people responded data quality was addressed through an initial screening of the volunteers. This ensured that they met the basic selection criteria discussed in the section on the research setting.

Within seven days 76 people who met the criteria had volunteered, at which point no further volunteers were accepted. Anticipating that some interviews would fail to happen, the first 63 were scheduled for interviews and the others, with their consent, put onto a reserve list. Some of these scheduled interviews could not take place and in the end 50 interviews were completed. Although no attempt was made to structure the sample on any demographic basis, a very diverse sample was obtained, measured on the basis of organisational level, gender, racial background, company size and industry sector.

A total of 19 executive-level, 23 professional-individuallevel and eight junior-level HR practitioners participated in the research. Companies in which they worked ranged from seven small companies (fewer than 150 employees), nine medium companies (150 to 1000 employees) and 19 large companies (1000 to 5000 employees) to 15 very large companies (more than 5000 employees). Many sectors of the economy were included, such as agriculture and timber, mining, manufacturing, construction, entertainment and hospitality, fishing and food, health, retail, financial and other services, telecommunications, state-owned enterprises, and higher education. Gauteng, Western Cape, Durban, and rural and small town locations were represented. Work settings were extremely diverse, and included the giant corporate headquarters of financial service companies, a timber mill deep in a forest, a small cell-phone tower construction company, a large fishing company, a power station, a university, a small computer services company and a large-scale catering company.

The focus group of volunteer HR executives included five people from companies that provided pharmaceutical services, utility services, consulting services, financial services and technical research.

\section{Data collection methods}

All data were collected in person by the researcher from November 2010 to March 2011. Individual face-to-face interviews of up to one hour were conducted with 14 of the informed commentators in Phase 1 of the study and telephone interviews of the same length with the other three, for geographic reasons. The interviews were semi-structured, and an interview protocol prepared from the literature review was used. The protocol was developed further as the interviews proceeded. Interviews were exploratory and nondirective and differed according to the field of expertise of the participant.

The interviews during Phase 2 were semi-structured and based on issues emerging from the Phase 1 interviews. Two pilot interviews were conducted, one face to face and the other by telephone, and as a result the interview protocol was adapted slightly. Of the main group of interviews, two were conducted face to face and 46 by telephone. Interviews were scheduled for 40 to 60 minutes, at a time which was convenient for the participant, and generally lasted for that length of time. Variations in the scope and length of the interviews occurred, depending on factors such as the availability of the participant, brevity of responses and depth of reflection. Data quality at this stage was ensured by using follow-up questions based on the researcher's in-depth knowledge of the field. 
The method used in the focus group was a discussion facilitated by the researcher and based on a short presentation of early findings of Phases 1 and Phase 2 of the research. Specific questions were addressed to the group, and a freeranging discussion ensued.

\section{Recording of data}

All the interviews as well as the focus group discussion were recorded on a digital recorder and transcribed verbatim by the researcher. Backups were kept of both the electronic data and the transcriptions. No loss of data occurred during the research study.

\section{Data analyses}

The main data analysis method used in this research study was a thematic analysis according to the guidelines laid down by Braun and Clarke (2006) and Henning (2004). Braun and Clarke, recognising that thematic analysis was widely used but poorly demarcated, set out some detailed guidelines for conducting such an analysis in a rigorous way, as well as some criteria for assessing the quality of the analysis.

The term 'theme' is therefore used in the sense of 'a level of patterned response or meaning within the data set' (Braun \& Clarke, 2006, p. 82). The general outline of the phases of a thematic analysis is to move from an overview to the generation of initial codes to a searching for themes. These themes are then reviewed, defined and named. Finally the report is produced by selecting extract examples and relating the analysis to the research objectives and literature.

Braun and Clarke discussed various approaches to theme identification. Some of the themes in this research study were identified in a data-driven way (they became manifest from participants' answers to questions) and some were derived from a theoretical framework based on the literature study. Also, some of the themes were identified on an explicit or semantic level (directly from what the interviewee actually said) and some on a latent level (only becoming apparent from an examination of underlying assumptions held by the interviewee). What might be termed a contingent approach to theme identification was therefore used.

Patton (2001) stated that a description of the data must be separated from an interpretation of the data. Therefore extracts from the interviews were grouped into broad themes before attempts were made to interpret them. In some cases, straightforward presentation of the data was possible from this grouping, for example, ideas on making a difference to the education system. In other cases, the topic was complex and data had to be interpreted and compared to other data before insights could be constructed. An example of these is attitudes to the contribution that HR work can make to society.

The integrity of the data analysis and interpretation was addressed, in view of the possibility of researcher bias, by using an independent co-researcher. This researcher, who has experience in qualitative analysis, reviewed all the Phase 2 interview transcripts and presented her independent analysis on some core issues. This was then discussed by the researchers. The 'golden thread' of argument arrived at by the principal researcher was reviewed by the co-researcher and she agreed that it was a valid interpretation of the data.

\section{Reporting}

The research study produced a considerable amount of data. This article deals with a sub-set of the research objectives and therefore only findings related to the topic of this article will be presented here. The research findings are reported by theme, using interview extracts and quotations where appropriate, to provide a clear and rich description of the perceptions of the participants.

\section{Findings \\ The impact of the environment}

In order to understand the extent of the impact of the external environment on the work of HR practitioners, the researcher asked Phase 2 participants in the study to estimate how much of their work was impacted by each of the following: 'specifically South African issues'; 'generic HR work demands'; and 'industry-specific or competitiveness or world class issues'. The term 'South African issues' was deliberately not defined, as the follow-up question asked the participant to name issues he or she thought would fall under that heading. The most prevalent view (18 responses) was that generic HR work demands had the biggest impact on their work, but 13 of the participants felt that 'South African issues' constituted a major impact on their work and 15 felt that 'South African issues' constituted perhaps around one third of the impact on their work.

The responses were highly influenced by level of employment, and the executives mostly felt that South African issues were highly significant. Most of the individual contributors felt that at least one third of their work was highly impacted, whilst none of the junior participants felt the impact of South African issues. The executive responses indicated a strategic view, for example:

'If you look at the political situation impact, the economic situation, unemployment, to a large extent, I mean it's huge, everything that we do is impacted by the events within the country' (Participant 6, male executive).

The 'South African' issues that were considered to have an impact on HR work included, in order of frequency of mention: education or skills development, legislation in general, employment equity, social and/or family problems, HIV and Aids and wellness, labour relations, debt and financial issues, BBBEE, crime, politics, the economy, transformation, inequality, and social responsibility. There were no obvious differences in frequency of mention of the different issues between the levels of participants. Many participants commented on the fact that employees brought their social problems to work with them and that this affected productivity, relationships at work and employee morale. 


\section{Attitudes to transformation}

Attitudes to transformation were explored in order to understand whether this was resisted, tolerated or welcomed by HR practitioners. Participants were positive about transformation and BBBEE requirements and felt that these national programmes helped them to promote transformation within their organisations:

'I feel strongly that, because certain groups of people in our society were denied educational opportunities, we will afford people those opportunities, even if they don't contribute to the company itself, but it's good for South Africa for us to do that' (Participant 29, male executive).

HR practitioners did, however, feel that business has been dragging its feet for years, and that the legislation was a good way to enforce change. This view was captured by two of the participants:

'If I use ourselves as an example, the BEE scorecard accelerated the implementation of the intentions, whereas before it was not executed at the rate that it would be. It becomes actually quite clear where it's best to invest in order to improve your score and that's what I'm saying is happening now' (Interviewee 36, male executive).

'Why is it that we're in the position we're in if we really believe that these things needed to be transformed. So to make it very concrete - some of these organisations sit with PDI representation at $30 \%$ and even if we just take the issue of our democracy - that's been 16 years, and why are we not seeing the kind of progress that we would expect if these things were readily embraced' (Interviewee 2, male executive).

\section{The contribution that HR work can make to society}

Do HR practitioners actually believe that their work can make a difference in society at large or do they believe the impact of their work is purely internal? The most common view (15 out of 34 responses) was that HR work did have an impact, but that its impact was limited to a 'ripple effect', for example:

'You find that people that are in employment are supporting a whole lot of unemployed family members and in some way, we're helping them to be resilient, that they then are able to influence the rest of the family because they in fact hold the family together' (Interviewee 47, female professional).

A minority (8) felt that their work had little or no impact, for example:

'I wouldn't say HR per se, is having an impact, our companies have an impact on greater society but not HR per se' (Interviewee 37 , female professional).

However, about one-third (12 people) felt that their work could have a significant impact on society. This view was more prevalent at the executive level ( 7 out of the 13 who discussed this point) and rare at individual contributor level ( 3 out of 18 ) and junior level ( 1 out of 5 ). The response of one executive demonstrates this line of thinking:

'I think it's quite vast really, and I can think about it from a macro and a micro level, because just looking at the HR work all down the line: generation of employment opportunities; wellness and wellbeing of people; literacy training and capacity building; how you engage people in the workplace which impacts their role and function in society; and change management affects interaction in society. So you might tend to think that you are doing something because it's your KPI but the impact of what you've done in the workplace actually has far-reaching implications on society' (Interviewee 25, female executive).

It seems that professional background makes a difference to whether HR practitioners view their work as contributing to society. The participants with a psychology or social worker background tended to have a narrower view of the impact of HR work on society than participants with an HRM or Sociology qualification. This effect was stronger at individual contributor level than at executive or junior levels.

HR practitioners seemed to 'walk the talk' about helping people. Voluntary community work where they used their professional skills was prevalent amongst HR practitioners, and about two-thirds of the people who were asked this question did undertake such work. Most of those who did not do voluntary work (one-third of the participants) said they would like to, but felt they had not identified suitable opportunities. Examples of voluntary work included: participation in faith-based organisations' social programmes, mainly HIV-related; advising people on labour law matters; career counselling in schools; mentoring small businesses on HR related matters; and mentoring young people.

\section{What needs to happen to enable HR practitioners to make a better contribution?}

The informed commentators interviewed in Phase 1 of the research felt strongly that HR practitioners were not as forceful and independent as they should be (and as they used to be in the 1980s):

'HR gets 2/10 on supporting, promoting, being activists to social policy issues. Part of SA's problem is the HR fraternity - it must move from a mindset of pessimism to a mindset of optimism, get excited, try to make a difference, every little bit can help' (Phase 1: Participant 7, male executive).

'HR often now don't think it's their place to care - that's for legislation and the unions - so HR is passive - it used to be different, they used to be persistent upfront change agents -

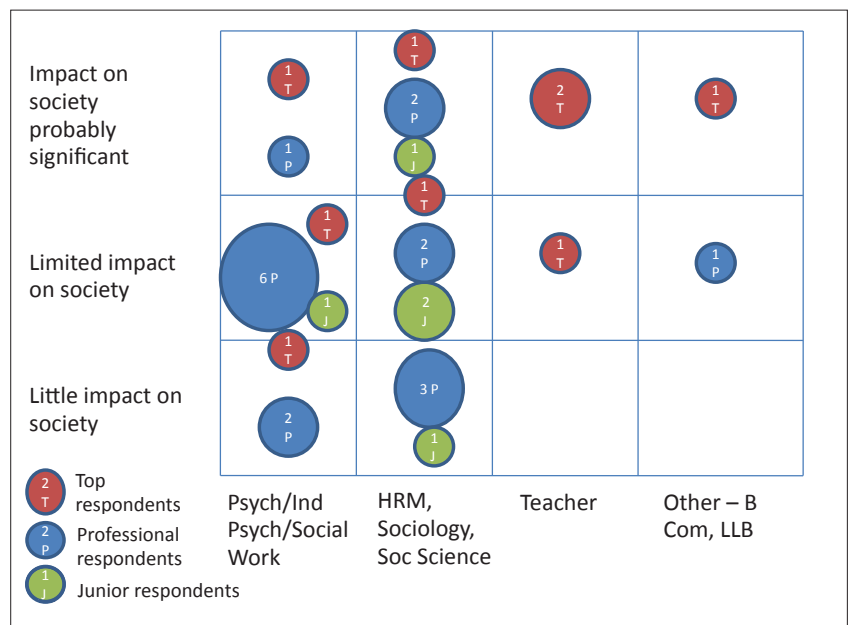

Source: Authors' own construction

FIGURE 3: Views on HR's contribution to society. 
they would come back bruised and go and fight again' (Phase 1: Participant 6, male executive).

Some Phase 2 participants agreed that great courage was required to make a difference:

'It takes a hell of an argument at Board level but people are basically good-hearted, so debate with them and let them see the link and what you're trying to achieve. Link society to business, that's the challenge of HR in this country - you have to have a fundamental awareness of the socio-economic dynamics around us and act on them - don't just have the awareness, but act on it but there is a lack of courage' (Participant 12, male executive).

'I suppose HR has for so long been told to become a business partner that HR has become maybe immune to those kinds of issues and HR wants so very badly to become a partner that we have abdicated that HR role to being called one of the boys' (Participant 12, female executive).

However, the chairperson of the SABPP, interviewed in Phase 1 of the research, was adamant that the role of business partner was in no way contradictory to that of an activist, and said that when you talked people issues, you were talking business issues:

You need to have the strength of mind to say what is the goal, where are we going. It's scary, it's very uncomfortable. But I'd rather be uncomfortable with you than uncomfortable with me. That's a choice I've made. I always say, if you want to be popular, don't be in HR. You have to keep your self-esteem, your self-worth, intact. If your locus of control is external, you're going to struggle.

Phase 2 participants made various suggestions as to why a better contribution was not made, and these included structural issues (HR resources were limited); approach issues (people did not see it as important and did not have the courage to raise the issue); and thinking skills:

'I think the HR community is so into their companies and the reason is that the majority of companies would like to operate with a very small HR structure, and therefore those individuals just have to get on and do their job for that company and that limits any ambition or need to try and do more than that because they are already stretched' (Interviewee 1, female executive).

'Most HR people, we look at business and we say that we're business people doing HR as opposed to being South African people in business doing HR' (Participant 3, male executive).

'HR people need to develop more spine, they have to be able to go to the CEO and say no, you are wrong, this is not the way to do it, and take the heat for it. Senior HR people see themselves as corks on life's ocean, their time is not their own' (Participant 11 , female executive).

'People are really not there, are really not thinking at a higher level. If you start thinking about levels of systemic thinking and levels of work, a lot of HR people, even at executive level, they're still at individual contributor level whereas they need to start moving more towards strategic intent' (Participant 25, female executive).

There are various channels through which HR can make a contribution, but it would seem that in many cases these channels are blocked. For example, it is common practice for the CSI function not to be part of the HR function or for the HR function to have no linkages at all with CSI.
This prevents the linkage between, for example, building recruitment pipelines and helping to develop better science teaching in schools. Another instance where practice could be more appropriate is in involvement in skills development. The extent of investment in learnerships varied widely amongst participants' companies and was seemingly independent of the size of the companies. No learnerships at all, discontinued learnerships and very limited learnerships were common occurrences. Only one participant mentioned that the company ran a learnership for disabled people. Few companies, even the large and very large, involved their staff in the governance structures of Sector Education and Training Authorities and even fewer got involved with Further Education and Training Colleges.

Some people felt that HR was too functional and narrow and was not responding to the imperatives of transformation. One participant lamented:

'I think we lack soul in HR, the human touch has gone, the social conscience is lost, it's a mean type of philosophy' (Participant 41, male professional).

But transformation is a strategic issue as much as a peoplecentred issue. This Phase 1 participant strongly believed that the strategic view is critical:

'HR people, when considering strategy, should bring in the social context for discussion - they need to be aggressive, spell out the realities out there, spell out the impact of certain policies and strategies - how they contribute to or alleviate social issues, force the debate - are we here for the long term - if so - we must contribute to society. Maybe this is a widening of the employee champion role' (Phase 1: Participant 4, male academic and consultant).

Some examples of ideas and current good practices in linking HR work to human development in society were forthcoming, although many Phase 2 participants had difficulty in thinking of practical ways in which these linkages could be made. Sufficient ideas were contributed during Phases 1 and 2 of the research to enable the construction of possible frameworks for action.

\section{Discussion}

The main objective of the study was to explore the linkage or alignment of HR practice in South Africa with its socioeconomic context and therefore with human development in this country. Since this is a topic on which no empirical research has been done, this study makes an initial contribution towards understanding how the linkages can be made and how HR practice can be improved. It is hoped that through this work the contribution of HR practice to the development of the quality of life for all South Africans can be enhanced.

If human development is to be measured more comprehensively than simply by means of economic progress, as discussed in the literature review of this article, then HR practitioners need to consider to what extent they can contribute, and are contributing, to the various factors of human development. Findings on the impact of the 


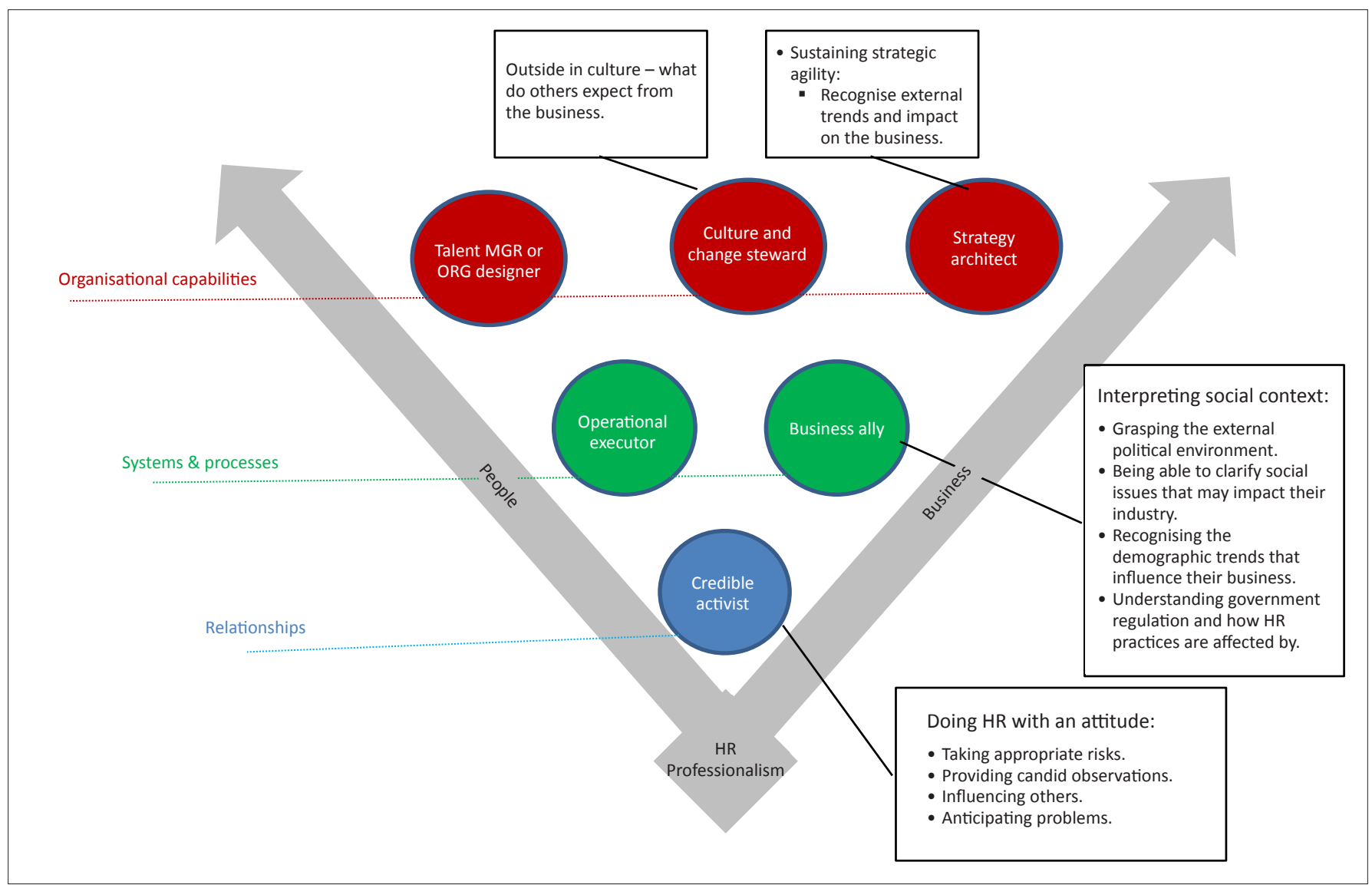

Source: Adapted from Ulrich, D., Brockbank, W., Johnson, D., Sandholtz, K., \& Younger, J. (2008.) Human Resource competencies: Mastery at the intersection of people and business. Alexandria, MA: Society for Human Resource Management

FIGURE 4: Competencies required by HR practitioners to connect appropriately with the socio-economic context.

socio-economic environment on HR work makes it clear that HR practitioners cannot isolate themselves from this environment. If they ignore the effects of social problems and the lack of human development they will be trapped in a spiral of ill-effects on the capabilities of future employees and they will continue to try to create productive, worldclass organisations in an environment increasingly incapable of fostering such organisations.

Participants in this research differed in their views on whether their work could make a difference in society. This shows that it cannot be taken for granted that individual HR practitioners, including executives, will see a need to make a difference and/or that they will feel able to take action to make a difference. HR education and training often prepare people to fulfil their internal, functional roles and do not sufficiently emphasise the need to impact on the environment. This was recognised by an HR academic interviewed in Phase 1 of the research, who said, 'Up to now we've been training [...] gofers - compliant functionaries. We don't develop HR people who have a social consciousness. Even strategic thinking is about the business.'

Teaching on the role of HR would typically include the work of Ulrich, whose work was discussed in the literature review. Ulrich's original conceptualisation of the role of Employee Champion was that it would be an internal role, seeking to balance demands on employees with improving the capability (resources) of employees to cope with those demands (Ulrich, 1997). The researchers subsequently developed the role to that of Employee Advocate, but still cast it as an internal role. Ulrich and Brockbank (2005) described the role as caring for, listening and responding to employees; ensuring inclusion of employee-related issues into management discussions and strategy debates; creating a culture supportive of diversity; and at the same time being tough on holding people accountable. The participants in this research in general raised points that supported Ulrich and Brockbank's view, but also felt that it was simply not possible to confine their attention to purely internal matters because of the symbiotic nature of the connections between an organisation's internal and external environment.

Ulrich et al. (2008) were the first to describe this interconnectedness in their work and they identified several related competencies in their competency model (see Figure 3), thereby acknowledging the contextual paradigm. Interestingly, these competencies are grouped in the 'business' dimension rather than the 'people' dimension of their model; maybe this underlines the fact that business is a social institution.

The interviews with thoughtful HR executives who viewed the field of HRM strategically revealed that they do in fact demonstrate these competencies, but there were several HR executives who did not see a wider role for HR and confined themselves to their internal role, albeit at a strategic, business level. The narrow, internal view demonstrated by the 
majority of individual contributors may not indicate a serious problem, because they are not expected to think strategically, but criteria for promotion to executive level may usefully be adapted to include some demonstration of understanding the connection between internal role and external impact.

The root of the problem may be the dynamics of HRM development South Africa since the 1980s, which has been driven extensively by economic and political forces. The development of HRM can be characterised by the following stages, as discerned by the researcher from personal experience and from the research interviews.

- 1980s: There was a tremendous expansion of HR influence and its strategic role, particularly in the large corporate and multi-national companies in South Africa. It was driven largely by labour relations and the socio-political developments of the transition to democracy. The 1980s were a period of great political unrest and the trade unions played a strongly political role, leading the opposition to apartheid. The workplace became one of the main battlegrounds for power. The response of employers, led by their HR heads, was to evolve sophisticated conflict resolution mechanisms to create and maintain peace in the workplace and in the surrounding communities in which their employees' families lived. These HR heads were often involved in the Peace Committees, where they contributed their knowledge of conflict resolution.

- 1990s: The strategic role of HR was diminished as the new government passed comprehensive employment legislation and the imperative became compliance. The reaction of business to the new government was partly one of relief, and business took a more passive approach to social reform, leaving it to the government to sort out. The emergence of organisation transformation functions centred on affirmative action, and the need to implement BEE diverted attention from the need to transform people. A tidal wave of global competition hit South African business as it emerged from international sanctions and a protected era, leading to a concentration on competitive issues, which were not seen as involving people development issues. At the same time, rapid technological advances caused the pace of change to accelerate and the world of work to become increasingly complex.

- 2000s: A divergence occurred in HR between:

- HR functions which became more strategic as businesses realised the centrality of people engagement to business competitiveness and the importance of sustainability.

- HR functions which became less strategic, bogged down in compliance issues and the difficulties of achieving significant changes in the demographics of their organisations (they ran out of 'quick wins').

- This divergence may have deepened because of a shortage of experienced HR executives, which sometimes led to the appointment of people with insufficient experience.

- 2010s: Corporate governance developments are now raising the bar on HR practice. This coincides with a realisation in South African society that the role of civil society needs to be regenerated to achieve real socio- economic transformation. A debate has therefore emerged within HR (as seen in the interviews for this research study) as to its ability to address these major issues of the times. Those HR functions which have over time become less strategic and bogged down in compliance issues will find it even more difficult to take on the new challenges. The skills gaps and lack of depth at senior HR levels, which were discussed by participants in this study, will also undermine the ability to respond.

The net effect of the recent decades has been that HR work has become much more focused on internal matters. The strategic role of HR is increasingly accepted, but organisations expect this strategic role to be exercised in relation to internal people issues. However, the changing nature of corporate governance demands that business pay more conscious attention to the socio-economic context in which it operates. HR practitioners will need to find ways to respond to these demands if they wish to remain at the forefront of developments.

The extent of the need to respond will probably depend on the levels of human development in a particular country. In more developed countries with high levels of human development, the external role of HR, although still present, will probably be less significant than in countries with low levels of human development. Also of importance, as Ulrich et al. (2008) discovered, is the level of maturity of the HR function itself - until the function has laid a sound foundation of people management practices inside an organisation, it cannot turn its attention to the external environment. The relationship of these factors is shown in Figure 5. In China, for example, the HR function has not yet matured and is still focusing on the basics of HRM. It is therefore unlikely that Chinese HR executives will have a basis from which to play a socially activist role. The HR function in South Africa, however, is generally mature and sophisticated, and HR executives should therefore be in a position to play such a role.

The range of factors impacting on human development can be wide, as has been seen. Even if a fairly narrowly defined measure such as the HDI is taken as a basis, there

\begin{tabular}{|c|c|c|}
\hline \multirow{3}{*}{$\begin{array}{r}\text { Maturity } \\
\text { of HR } \\
\text { function }\end{array}$} & $\begin{array}{l}\text { HR practitioners should } \\
\text { play the People Advocate } \\
\text { role, leveraging credibility } \\
\text { earned because of } \\
\text { internal effectiveness }\end{array}$ & $\begin{array}{l}\text { Less need for HR } \\
\text { practitioners to play the } \\
\text { People Advocate role, } \\
\text { but they should not } \\
\text { forget their Employee } \\
\text { Advocate role }\end{array}$ \\
\hline & $\begin{array}{l}\text { HR practitioners need to } \\
\text { build the function first, } \\
\text { playing the Employee } \\
\text { Advocate role, and then turn } \\
\text { attention to the broader } \\
\text { People Advocate role }\end{array}$ & $\begin{array}{l}\text { HR practitioners should } \\
\text { build the function internally } \\
\text { and ensure they play the } \\
\text { Employee Advocate role as } \\
\text { they do so }\end{array}$ \\
\hline & Level of hum & evelopment \\
\hline
\end{tabular}

Source: Authors' own construction

FIGURE 5: Relative importance of the People Advocate role. 


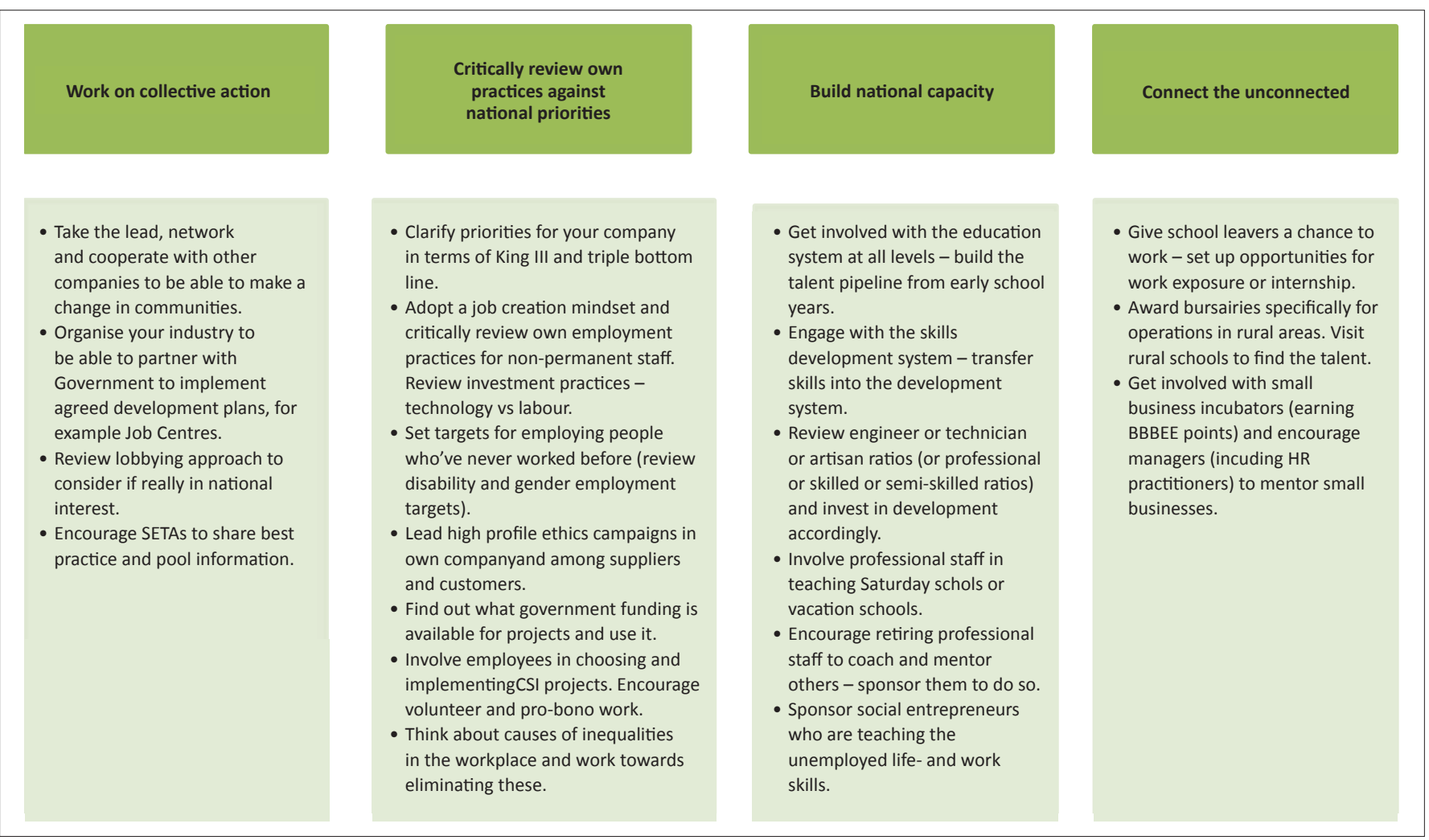

Source: Authors' own construction

FIGURE 6: Possible elements of a response at a strategic level in an organisation.

are a number of nested cause-and-effect relationships on the factors of longevity, knowledge and income. If the GNHI is taken as a measure, many more factors are involved. This research study has not attempted to draw direct linkages between each factor of human development and HR work, but at a more aggregated level two frameworks of possible HR actions have been developed from the study. The first framework is for strategic use in an organisation and the second for individual HR practitioners. These frameworks are a preliminary formulation of what could be possible, and are offered for debate and further development. The two frameworks are shown in Figures 6 and Figure 7.

\section{Outline of the results}

This research study has been a journey of exploration and discovery in the lived reality of contemporary HR practice in South Africa. The researcher has been able to move towards linking the problems of lack of human development in our society to the realities of HR practice in the workplace. It has become clear that at present HR practitioners seldom put in place strategies and programmes to deal with these problems. To this extent, current HR practice can be considered as elitist. However, HR practitioners do not work in isolation because the effects of the lack of human development in South African society impact heavily on their daily work.

A reformulated role for HR practitioners, adapted from the original Employee Advocate role put forward by Ulrich and Brockbank (2005), is proposed - that of People Advocate.

Improve your skills
- Improve your knowledge of the context and its impacts
Strenthen the profession
- Join and support professional bodies
Monitor impact of context
- Observe, collect information (for example, on effect of debt) and report to management
Make an effort
- Find more ways to assess the potential of an unemployed person
- Find new channels for recruitment to give opportunities to people without normal access
- Challenge managers to create entry level jobs
- Take time to counsel people in the workplace
- Notice whether people are struggling and intervene to help them
Contribute ideas
- Think about the issue and make suggestions
Do voluntary work
- Volunteer in the community, using your HR skills

Source: Authors' own construction

FIGURE 7: Possible elements of a response at an individual HR practitioner level.

This role works both internally and externally alongside that of Human Capital Developer, which takes on a wider meaning and covers human capital in the pipelines and the general societal context, as well as within the company. In this new formulation the other two roles in the 2005 model, Functional Expert and Strategic Partner, remain unchanged and within the organisational context (see Figure 8).

The HR leader is the point of intersection of the organisation and its wider societal context, as the leader must focus the societal context for the company context, but this positioning 
of the People Advocate and Human Capital Developer roles for all HR practitioners could give more meaning to their work. These roles can be based on the idea that 'human resources is a crucial point of intersection between the broader society and business' (researcher's emphasis) (Capelli \& Yang, 2010, p.1). Several participants in the study felt concerned because topics of this nature were seldom discussed within the profession and expressed the hope that this research study would be the beginning of a more thoughtful approach in this area.

The main recommendation emerging from the study is that the research report, which contains many subrecommendations, be tabled and discussed at the SABPP. It is hoped that more research will be done in this area and clear policies and guidelines laid down for the HR profession. Incorporation of human development issues into the curriculum of tertiary education in the field of HR would also support a broader view on the part of HR practitioners. It is further recommended that more academic work and books on relevant aspects of human development be published within the HR field to enhance awareness of the issues involved.

\section{Limitations of the study}

The aim of this study was to explore the topic using qualitative methods and seek to understand some of the issues involved. The self-selection of Phase 2 participants may have biased the responses towards social activism, and the lack of inclusion of other stakeholders such as line managers, Boards of Directors, and communities may have resulted in missing some of the issues involved. However, the responses given by the participants, and the insights gained from them, will be recognisable to a wide range of HR practitioners and it is therefore hoped that the study will ignite further discussion of the issues relevant to HR and human development.

\section{Suggestions for further research}

Research is suggested under the auspices of the SABPP to develop the frameworks proposed in this article and to

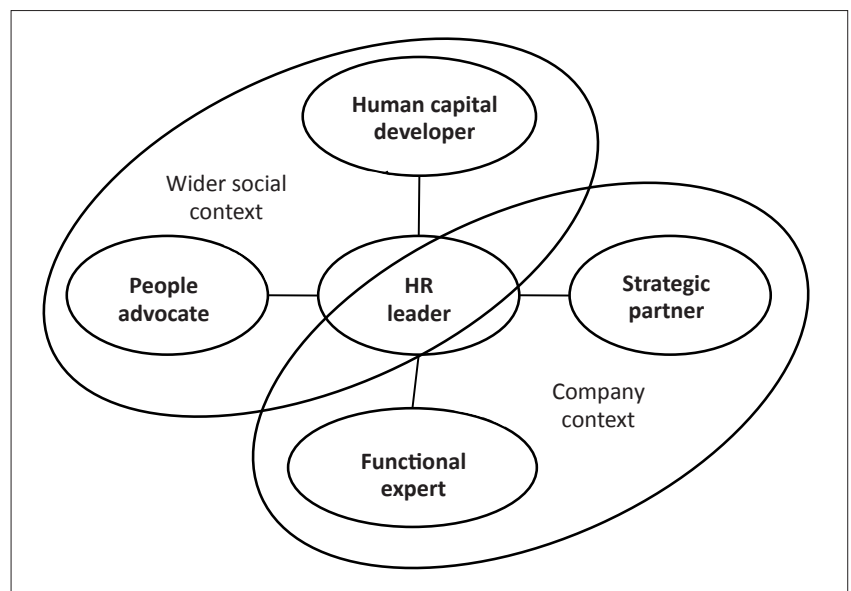

Source: Adapted from Ulrich, D., \& Brockbank, W. (2005). The HR value proposition. Boston, MA: Harvard Business School Press

FIGURE 8: Roles of the HR leader. compile a feasible index of human development, containing factors that HR practitioners can contribute to directly. From such research it may be possible to draw a system diagram of the linkages between HR work and human development. This would allow tracking to be done and interventions in this area to be managed.

\section{Conclusion}

There is a groundswell of concern in South Africa that our social system is failing to deliver acceptable progress on improving the quality of life of the majority of our population. The national development plan of 2012 provides a framework within which the part that organisations, whether private sector, public sector or NGOs, need to play is clearly set out. This can provide HR practitioners with the opportunity to take a lead in integrating their workplace with the society around them and in so doing, provide meaningful programmes to improve the human capital value chain both within and outside their organisations. Taking up the Employee Advocate role will not be easy, but it could be one of the most meaningful steps for any HR practitioner to take.

\section{Acknowledgements Competing interests}

The authors declare that they have no financial or personal relationships which may have inappropriately influenced them in writing this article.

\section{Authors' contributions}

This article was written equally by P.A. (University of Johannesburg) and reviewed by J.C. (University of Johannesburg) and X.G. (University of Johannesburg).

\section{References}

Bernstein, A. (2010). The case for business in developing economies. Johannesburg: Penguin Books.

Boninelli, I., \& Meyer, T. (2011). Human capital trends - Building a sustainable organisation. Randburg: Knowres Publishing.

Braun, V., \& Clarke, V. (2006). Using thematic analysis in psychology. Qualitative Research in Psychology, 3, 77-101. http://dx.doi.org/10.1191/1478088706qp063oa

Brewster, C. (2007). Comparative HRM: European views and perspectives. International Journal of Human Resource Management, 18(5), 769-787. http:// dx.doi.org/10.1080/09585190701248182

Bryman, A., \& Bell, E. (2003). Business research methods. Oxford: Oxford University Press.

Caelli, K., Ray, L., \& Mill, J. (2003). 'Clear as mud': Toward greater clarity in generic qualitative research. International Journal of Qualitative Methods, 2(2), 1-13.

Capelli, P., \& Yang, Y. (2010). Who gets the top job? Changes in the attributes of Human Resource heads and implications for the future. Retrieved January 02, 2011, from http://www.pwc.com/en_US/us/people-management/assets/hr-leaderattributes.pdf.

Crous, W. (2010, January). Challenges to the HR Fraternity: 2010 and beyond. Paper presented at the University of Johannesburg Study School, Johannesburg.

EE Commission (2010). Commission for Employment Equity Report 2009-2010. Retrieved July 20, 2011, from http://www.labour.gov.za/documents/annualreports/Commission\%20for\%20Employment\%20Equity\%20Report/2009-2010/ commission-for-employment-equity-report-2009-2010/?searchterm=employme ntequityreport2009

Evans, P. (2002). Collective capabilities, culture and Amartya Sen's development as freedom. Studies in Comparative International Development, 27(2), 54-60. http:// dx.doi.org/10.1007/BF02686261

GNHI (2011). Gross National Happiness Index. Retrieved January 03, 2011, from http://www.grossnationalhappiness.com/gnhlndex/intruductionGNH.aspx

Henning, E. (2004). Finding your way in qualitative research. Pretoria: Van Schaik. 
IOD (2009). IoDSA King III Report. Retrieved January 04, 2011, from http://www.iodsa. co.za/products_reports.asp?CatID $=150$

Jackson, T. (2004). Management and change in Africa: A cross-cultural perspective. Abingdon: Routledge.

McGaughey, S.L., \& de Cieri, H. (1999). Reassessment of convergence and divergence dynamics: Implications for international HRM. International Journal of Human Resource Management, 10(2), 245-250. http://dx.doi. org/10.1080/095851999340530

Merriam, S.B. (1998). Qualitative research and case study applications in education. San Francisco, CA: Josey Bass.

Mills, G. (2010). Why Africa is poor and what Africans can do about it. Johannesburg: Penguin Group

$\mathrm{Nel}, \mathrm{C} .(2010)$. Transformation without sacrifice - the urgency of social, economic and organisational justice in South Africa. Cape Town: Village of Leaders Products.

NPC (2011). Diagnostic overview. Retrieved July 10, 2011, from http://www. thepresidency.gov.za

Patton, M.Q. (2001). Qualitative research and evaluation methods. (3rd edn.) Thousand Oaks, CA: Sage.

Pugh, D.S., \& Hickson, D.J. (2000). Great writers on organizations. (2nd omnibus edn.) Brookfield, VT: Ashgate.

Ramphele, M. (2008). Laying ghosts to rest: Dilemmas of the transformation in South Africa. Cape Town: Tafelberg. PMid:18352944

Republic of South Africa (2008) Companies Act, No. 71 of 2008. Retrieved July 19, 2011, from http://www.thedti.gov.za.

Rodriguez, F.R. (2010). Trends in human development. On-line paper for the United Nations Development Programme. Retrieved April 30, 2010 from http://hdr.undp. org/en/mediacentre/lets-talk-hd/

Sibiya, B. (2010, March). Emerging market economies - The opportunities, challenges \& responsibilities for human capital management. Paper presented at the Knowledge Resources Human Resources Directors Conference, Johannesburg. PMCid:PMC3031840
Temkin, S. (2010, 19 October). Shortage of artisans 'playing a key role in poor service delivery'. Business Day, p. 3.

Thompson, C. (2011, 11 July). State and unions trapped in adversary roles. Business Day, p. 9.

Todaro, M.P., \& Smith, S. C. (2006). Economic development. 9th edn. Harlow: Pearson Education. PMCid:PMC2631550

Toulson, P.K., \& Defryn, M.K. (2007). The development of Human Resource Management in New Zealand. New Zealand Journal of Human Resource Management, 7, 75-103.

Turok, B. (Ed.). (2008). Wealth doesn't trickle down: The case for a developmental state in South Africa. Cape Town: New Agenda: South African Journal of Social and Economic Policy.

Ulrich, D. (1997). Human resource champions: The next agenda for adding value and delivering results. Boston, MA: Harvard Business School Press.

Ulrich D., \& Brockbank, W. (2010). The business partner model: Past and future perspectives. Human Capital Review. November, 2010.

Ulrich, D., \& Brockbank, W. (2005). The HR value proposition. Boston, MA: Harvard Business School Press.

Ulrich, D., Brockbank, W., Johnson, D., Sandholtz, K., \& Younger, J. (2008.) Human Resource competencies: Mastery at the intersection of people and business. Alexandria, MA: Society for Human Resource Management.

Ulrich, S., Younger, J., Brockbank, W., \& Ulrich, M. (2012). HR from the outside in. New York, NY: McGraw-Hill.

United Nations Development Programme (UNDP). (2010a). Rankings on the HDI Retrieved April 30, 2010, from http://hdr.undp.org/en/statistics/data/

United Nations Development Programme (UNDP). (2010b). The Human development concept. Retrieved March 01, 2010, from http://hdr.undp.org/en/humandev/

United Nations Development Programme. (2011). Human Development Report Retrieved July 06, 2011, from http://hdr.undp.org/en/data/explorer/ 